\title{
درجة ممارسة معلمي اللغة الإنجليزية لمهارات التعلم الإلكتروني في دولة الكويت
}

\author{
أديب ذياب حمادنة \\ أستاذ في مناهج اللغة العربية وأساليب تدريسها- جامعة آل البيت- الأردن \\ adeebhamadnah@yahoo.com \\ غزيل بدر الغصياب \\ معلمة اللغة الإنجليزية-وزارة التربية- الكويت
}

هدفت الدِّراسة التعرف إلى درجة ممارسة معلمي اللغة الإنجليزية لمهارات التعلم الإلكتروني في دولة الكويت. وأثر متغيرات (الجنس، والمؤهل

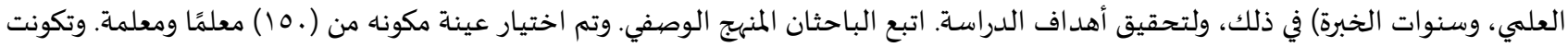

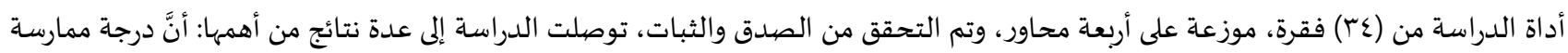

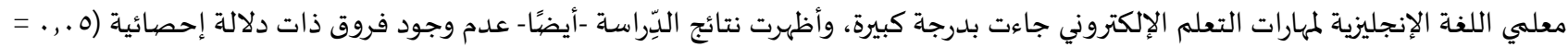

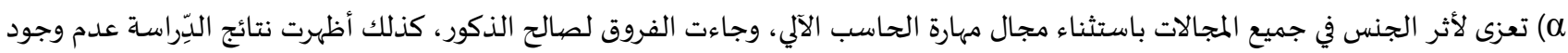

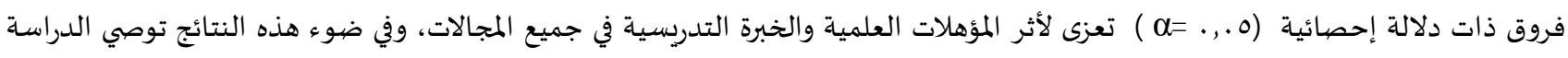
بإجراء دورات تعليمية مستمرة للمعلمين في مجال تكنولوجيا التعليم وكيفية. الكلمات المفتاحية : درجة الممارسة، مهارات التعلم الإلكتروني، معلمي اللغة الإنجليزية.

\section{(c) (1)}

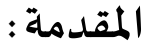

يتميز هذا العصر بالتغيرات السريعة الناجمة عن التقدم العلمي والتكنولوجي وتقنية المعلومات، لأنَّ التكنولوجيا تتوغل في ميادين الحياة عامة.

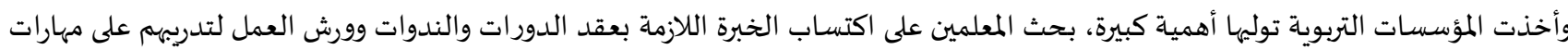
التعلم الإلكتروني ليتمكنوا من صقل موهبتهم بما يتلاءم ومحتوى المادة الدِّراسية، لنقل الطلبة من الروتين اليومي إلى أجواء علمية جديدة، فتعددت

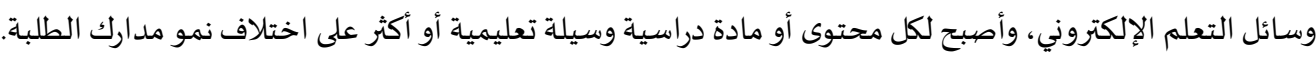

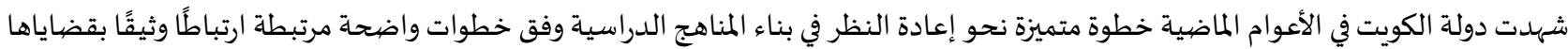

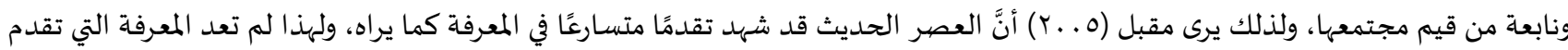

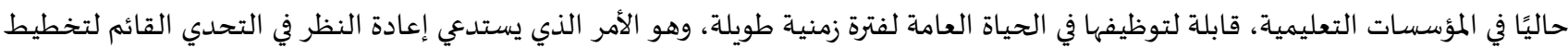

وتحتل المناهج اليوم مركزًا هامًا في العملية التربوية، وتعد المناهج أداة التربية ووسيلتها في تحقيق أهدافها، ونظراً لهذه الأهمية كان لأي نظام

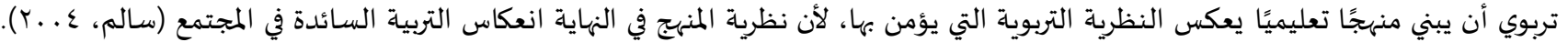

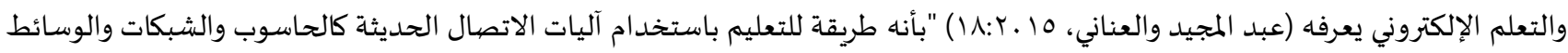
المتعددة من أجل إيصال المعلومة للمتعلمين بأسرع وقت وأقل كلفة وبصيورة تمكن من إدارة العملية التعليمية وقياس وتقييم أداء المتعلمين". 
وقد أحدثت أنظمة التعلّم الإلكتروني تغييرات ملحوظة في التعليم والتدريب، خصيوصًا تطور أنظمة التعلم القائم على شبكة الإنترنت التي منحت

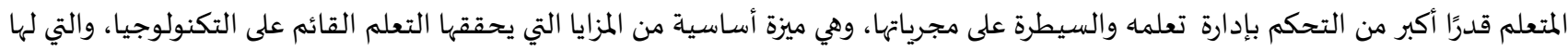
تأثير إيجابي في زيادة فعالية التعلم الإلكتروني (Sorgenfrei \& Smolnik, 2016).

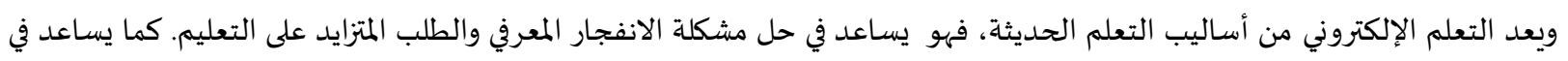
حل مشكلة ازدحام قاعات المحاضرات إذا استخدم بطريقة التعلم عن بُعد، وتوسيع فرص القبول فئل في التعليم، والتمكن من تدريب وتعليم العاملين

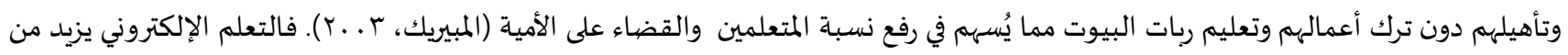

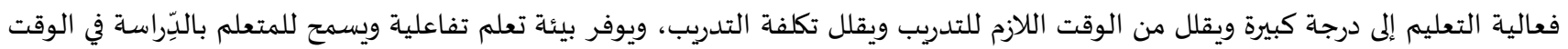

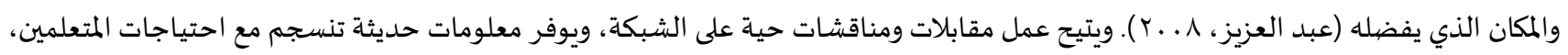
ويوفر برامج المحاكاة والصور المتحركة وفعاليات وتمارين تفاعلية وتطبيقات عملية (الدليمي، 10 ـ. (ب).

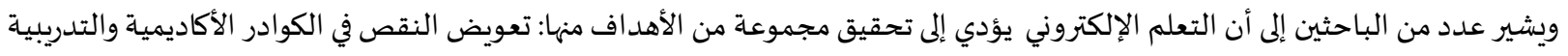

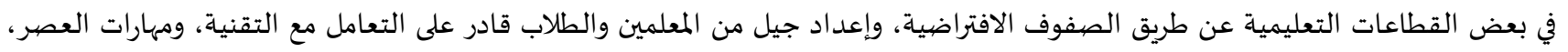
والتطورات الهائلة التي يشهدها العالم، وتوفير بيئة تفاعلية غنية ومتعددة المصادر تخدم العملية التعليمية بكافة محاورها، وفتح المجال أمام الطلبة

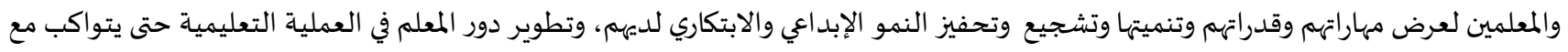
التطورات العلمية والتكنولوجية المستمرة والمتلاحقة، والمسـاعدة على نشر التقنية في المجتمع وإعطاء مفهوم أوسع للتعليم المستمر، ودعم عملية

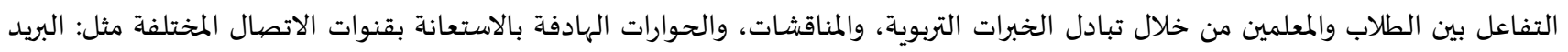

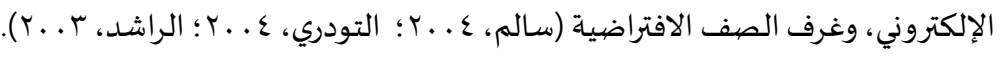
وفي ذات السياق يشير إسلام وبير وسلاك (Islam, Beer \& SlacK, 2015) إلى أن معظم الباحثين في موضوع التعلم الإلكتروني ركزوا على

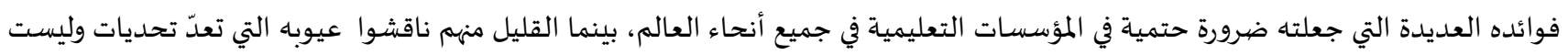

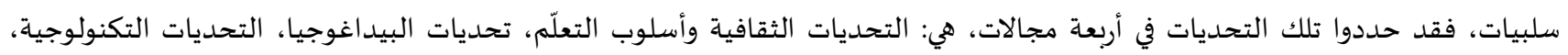
تحديات التدربب التقني.

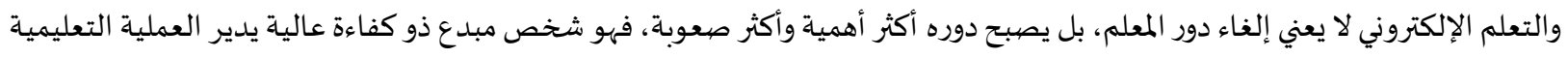

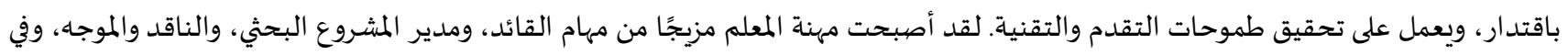

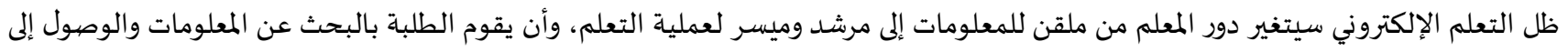

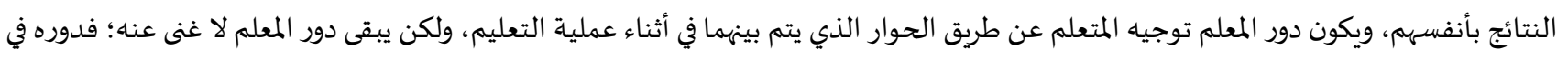

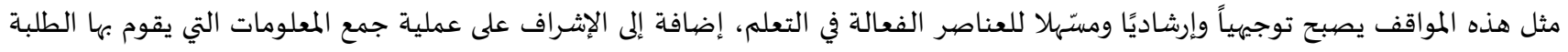

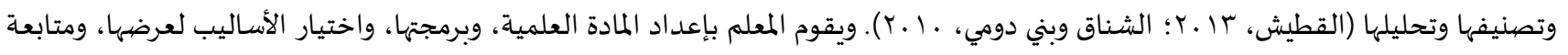

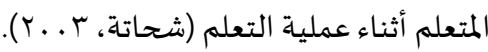

ويعد المعلم أحد العناصر الهامة التي يقوم عليها نظام التعلم الإلكتروني (الحلفاوي، ج ج . ب). إذ يشكل المعلم حجر الزاوية في العملية التعليمية.

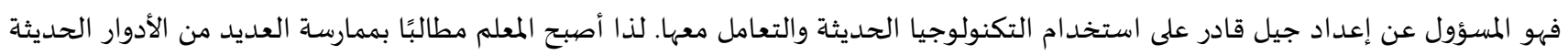

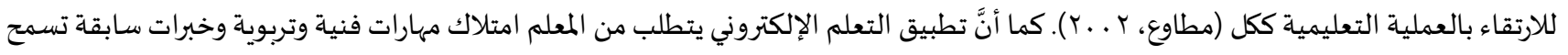

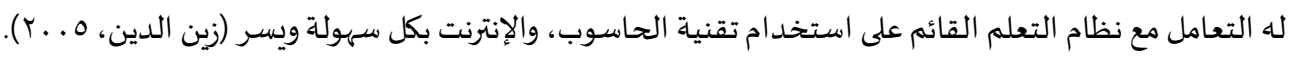

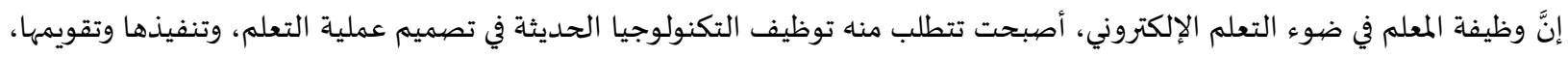

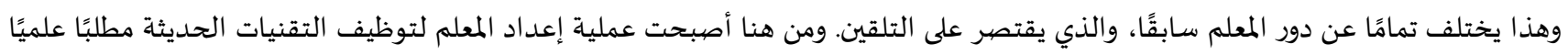

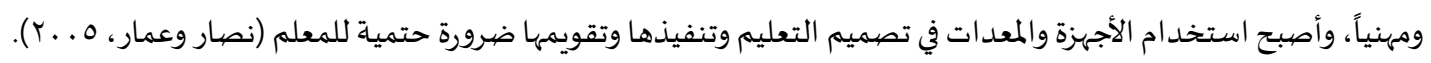

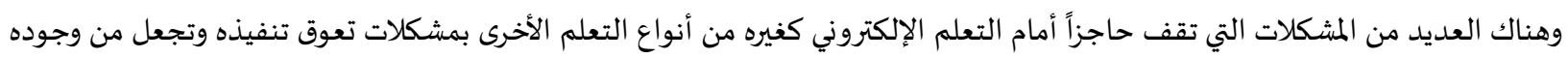

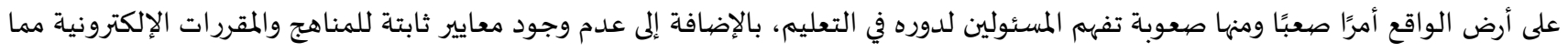

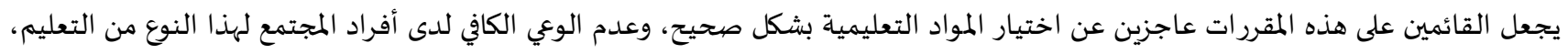

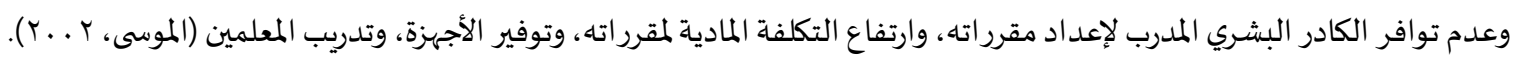

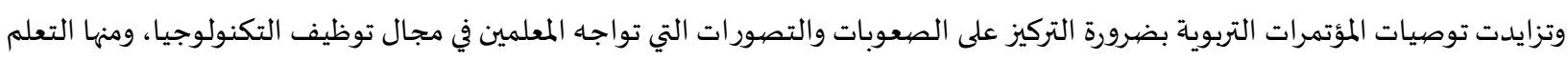

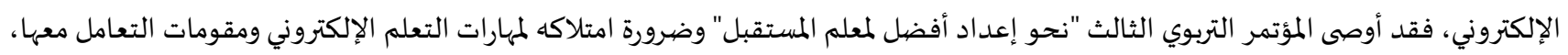
من أجل مساعدته على استخدامها في المواقف التعليمية المتعددة (مدكور، ع ع . ب). 
وقد تناول الباحثان عددًا من الدِّراسات ذات الصلة بالدِّراسات العربية والأجنبية وهي مرتبة من الأقدم إلى الأحدث ومنها دراسة العمري (ج . ب)

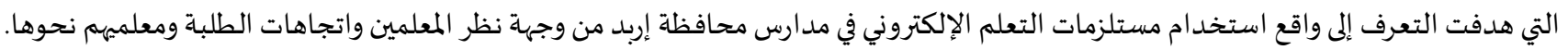
تم بناء استبانتين الأولى للطلبة ومكونة من (1) فقرة وتقيس اتجاهاتهم نحو التعلم الإلكتروني، أما الاستبانة الثانية فكانت للمعلمين، وتكونت من

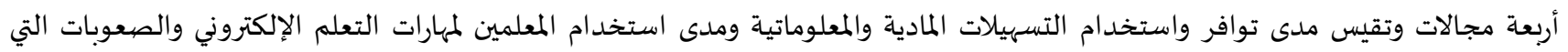

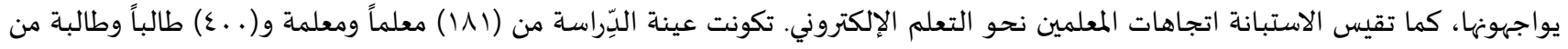

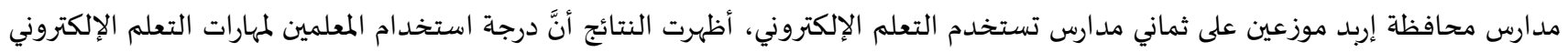

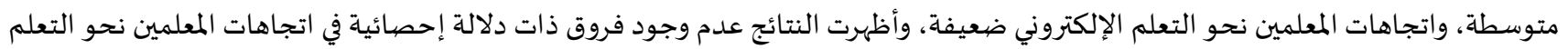

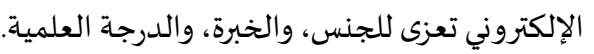

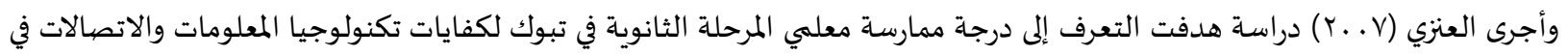

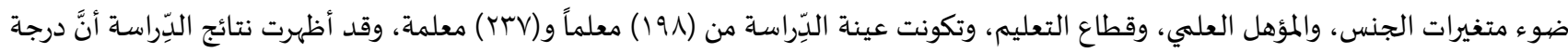

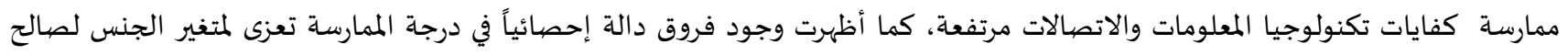

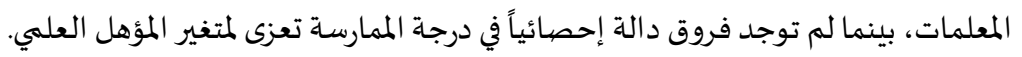

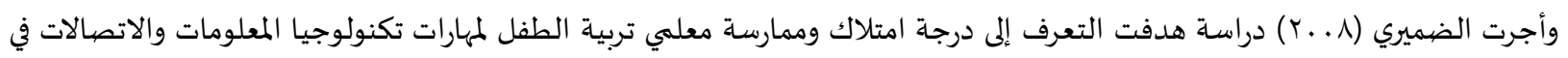

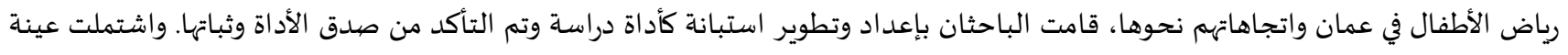

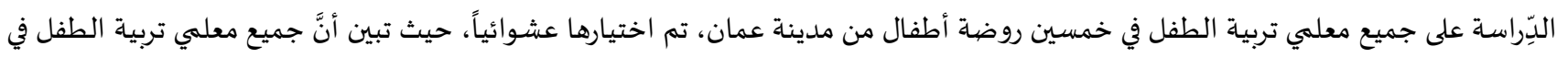

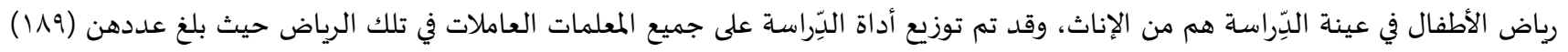

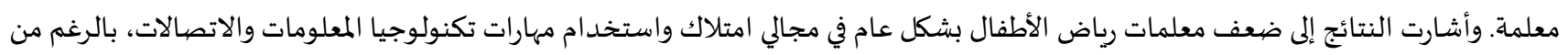

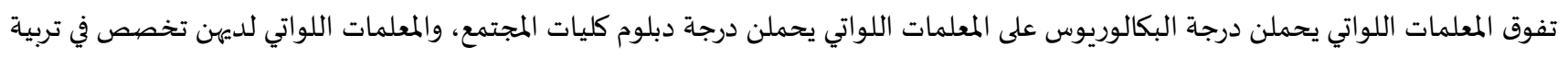

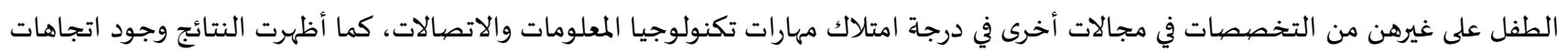

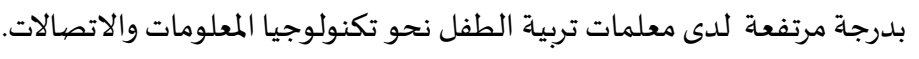

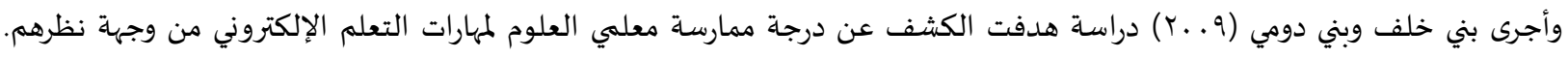

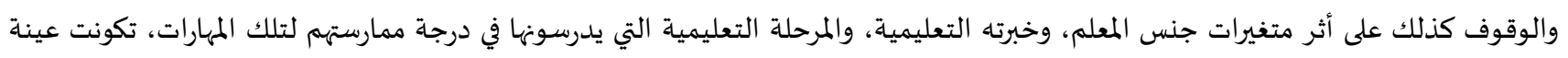

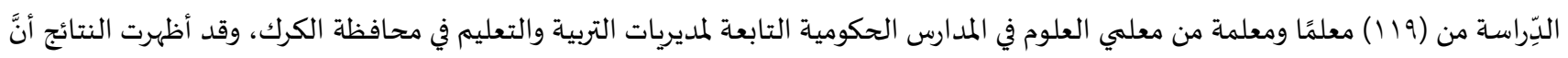

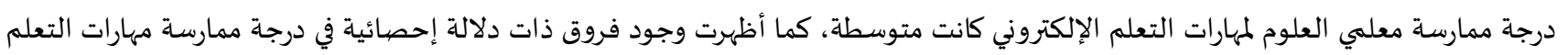

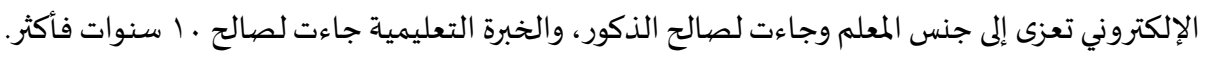

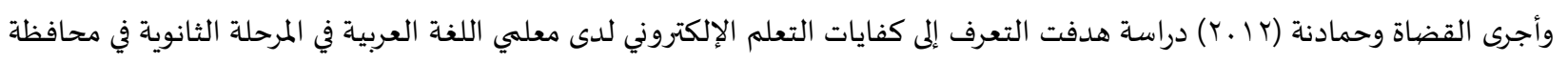

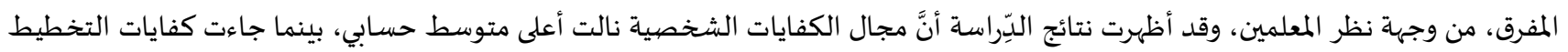

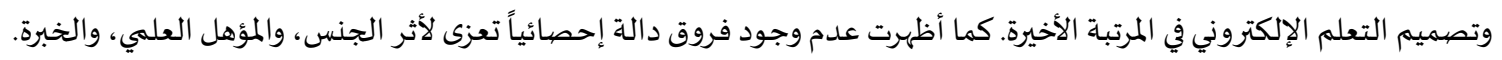

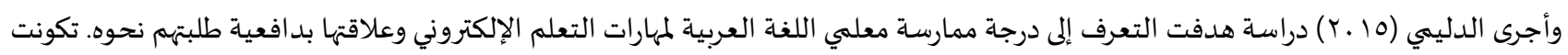

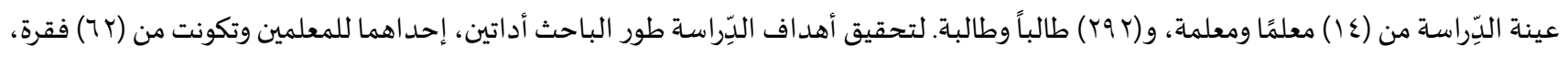

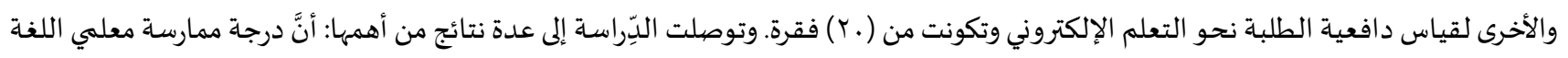

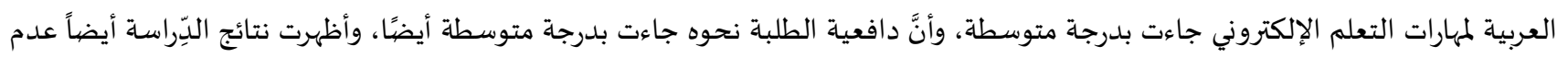

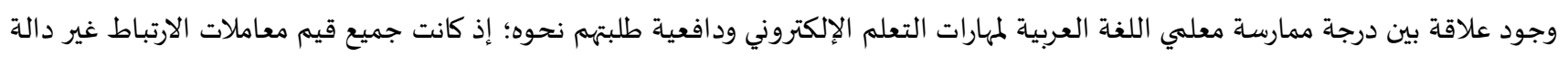

إحصائياً.

وأجرى ماكوها وموتيسيا (Makokha \& Mutisya, 2016) دراسة هدفت تقييم حالة التعلم الإلكتروني في الجامعات الحكومية في كينيا، وتم

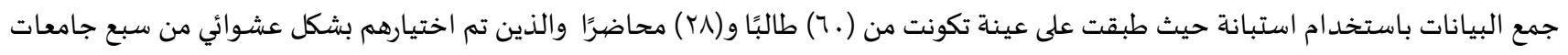

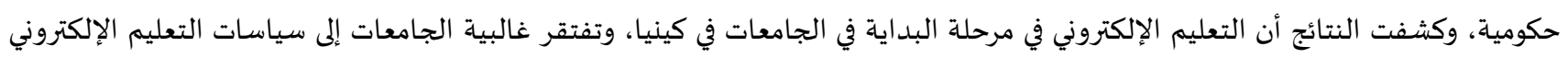

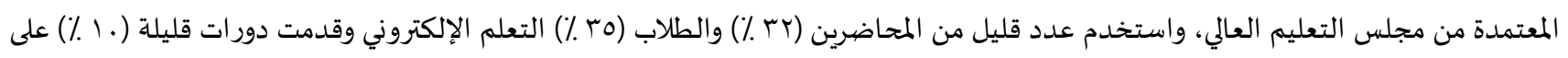

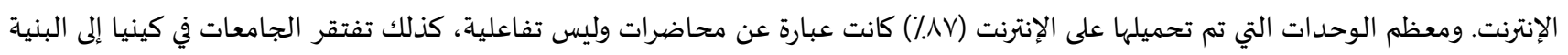

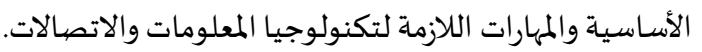


وأجرى اوبيكو وإز (Obuekwe \& Eze, 2017) دراسة هدفت إلى استكشاف آفاق وتحديات التعلم الإلكتروني نحو تعزيز أفضل الممارسات في

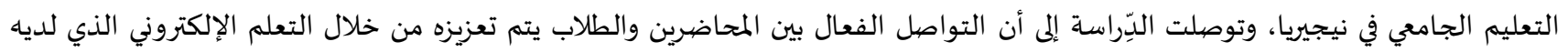

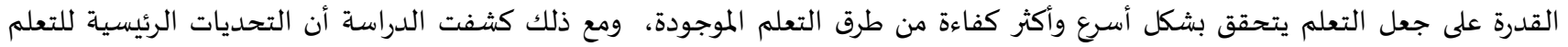

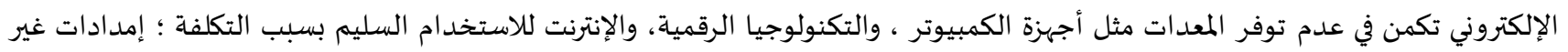
منتظمة من الكهرباء، ونقص المهارات التقنية اللازمة لتنفيذ التعلم الإلكتروني.

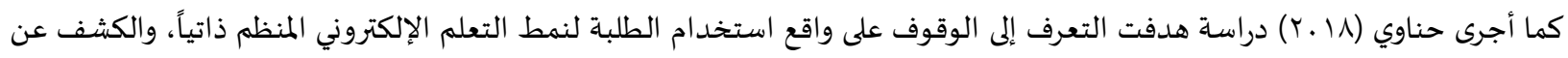

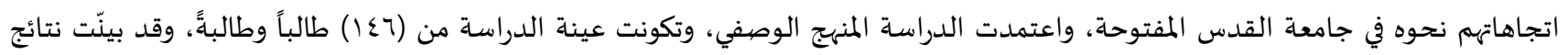

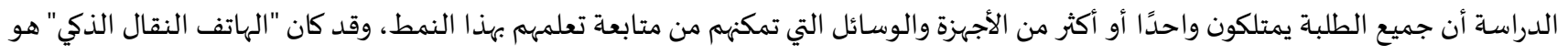

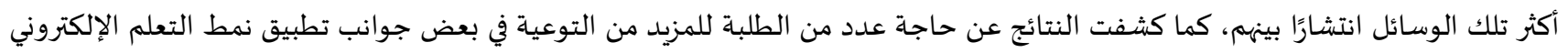

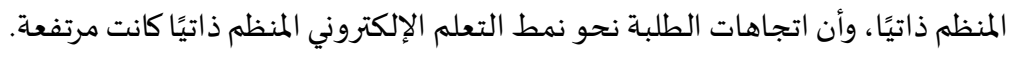

التعقيب على الدِّراسـات السـابقة:

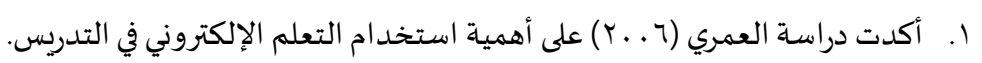

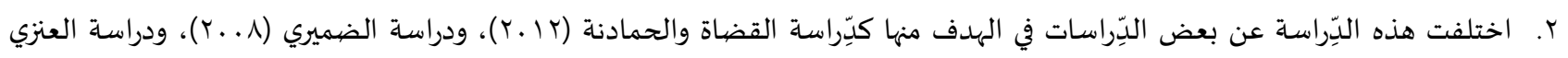

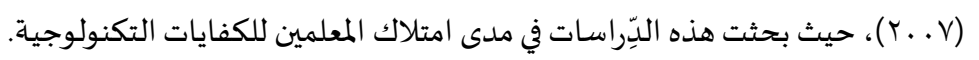

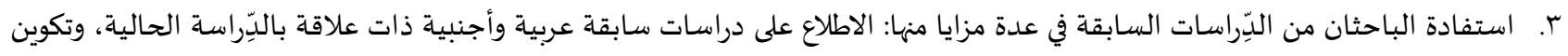

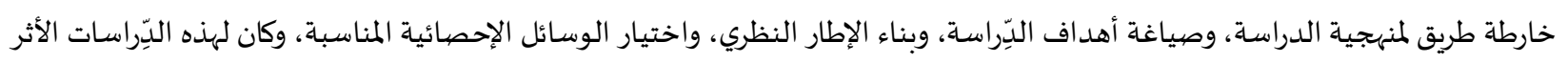
الكبير في هذه الدِّراسـة الحالية. ع. اتفقت هذه الدِّراسة مع دراسة الدليمي (10 ـ ب) في تناولها درجة ممارسة معلمي اللغة العربية لمهارات التعلم الإلكتروني وعلاقتها بدافعية طلبتهم

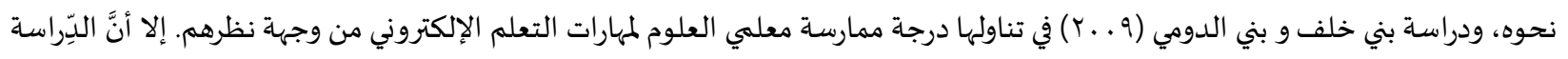

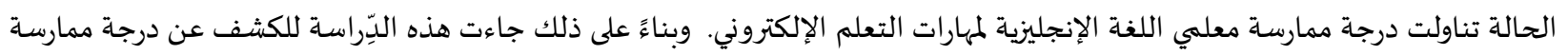

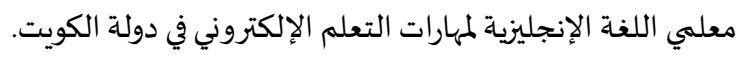

مشكلة الدِّراسة وأسئلتها: يطلق على العصر الذي نعيشـه الآن عصر التكنولوجيا التي غيرت الكثير من أساليب وطرق حياتنا الحالية بما فيها التربية والتعليم، ويعد التعلم التها

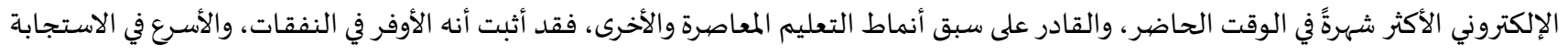

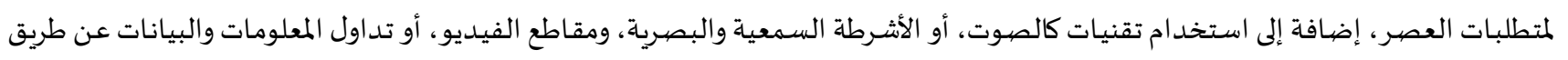

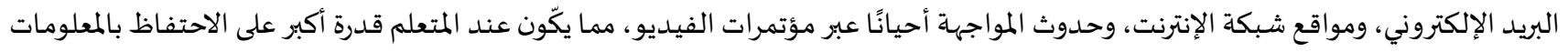

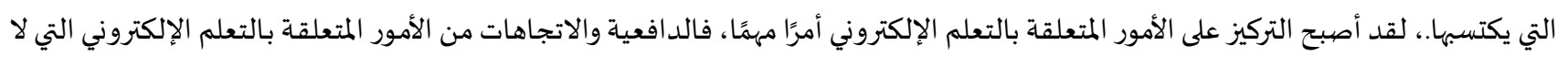

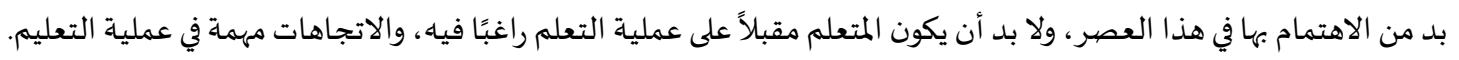

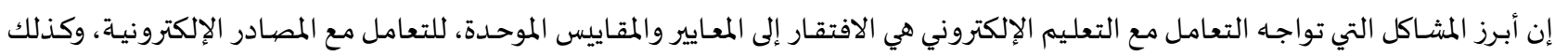

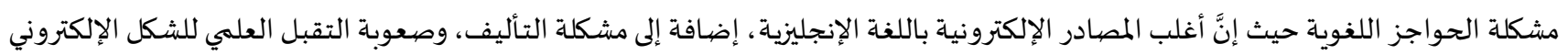

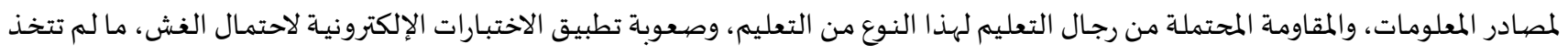

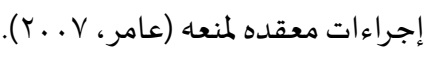

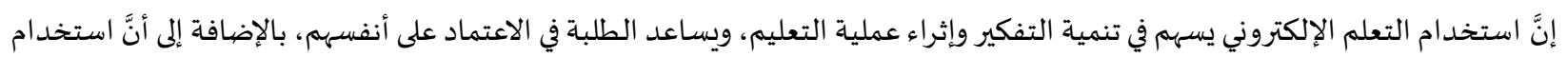

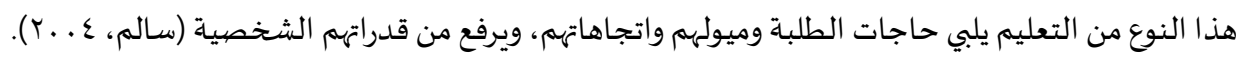

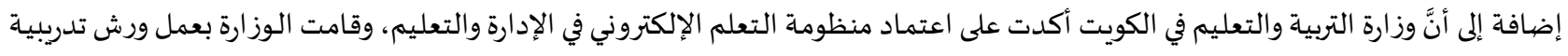

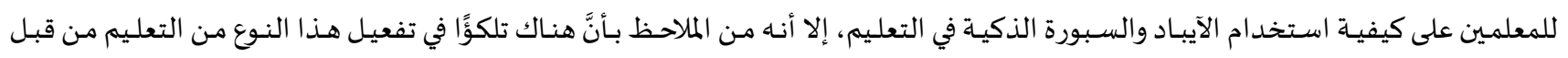
المعلمين، وفي ظل اعتماد وزارة التربية والتعليم لهذا النوع من التعليم، ومن هنا جاءت مشكلة الدِّراسـة والمتمثلة بالإجابة عن أسئلتها الآتية. 


\section{أسئلة الدِرِاسـة: \\ ! . ما درجة ممارساة معلمي اللغة الإنجليزية لمهارات التعلم الإلكتروني؟ ץ. هل تختلف درجة ممارسة معلمي اللغة الإنجليزية لمهارات التعلم الإلكتروني باختلاف (الجنس، والمؤهلات العلمية، والخبرة التدريسية)؟}

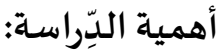

تنبع أهمية هذه الدِّراسـة من أهمية الموضورع الذي تتناوله، بالإضيافة إلى ذلك فمن المتوقع أن تسهم هذه الدِّراسة بالآتي: تقدم هذه الذِّراسة معلومات وافية للقائمين على العملية التربوية حول درجة ممارسـة معلمي اللغة الإنجليزية لمهارات التعلم الإلكتروني. تبين هذه الدِّراسة أهمية التعلم الإلكتروني في تدريس اللغة الإنجليزية.

$$
\text { هدفت الدراسـة التعرف إلى ما يلية }
$$

التعريفات الإجرائية:

درجة الممارسة: هي الممارسة العملية لمهارات التعلم الإلكتروني التي يحددها معلهم اللغة الإنجليزية وتقاس بالدرجة التي يحصل عليها من خلال إجابته عن فقرات الاستبانة المعدة لهذا الغرض.

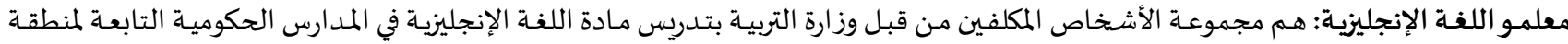

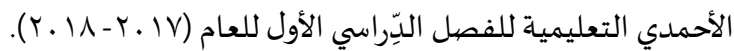
مهارات التعلم الإلكتروني: هي مجموع الإجراءات والمبادئ والقدرات التي يستخدمها المعلم مع طلبتـه عن طريق استخد امه للتعلم الإلكتروني، لضيمان

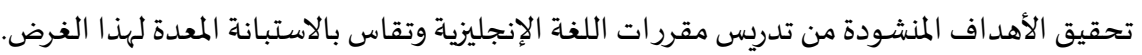

حدود اللدّراسـة ومححدداتها:

تتمثل حدود الدِّراسة الحالية ومحدد اتها فيما يلي:

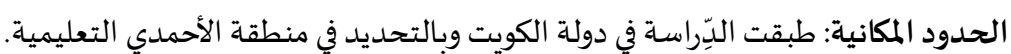

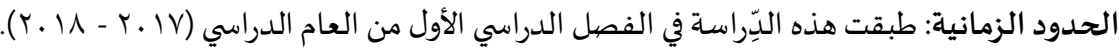
الحدود البشرية: طبقت الدِّراسة على معلمي اللغة الإنجليزية الذين يدرسون الدرانية منهاج اللغة الإنجليزية للمرحلة الثانوية في منطقة الأحمدي التعليمية. الحدود الموضوعية: اقتصرت هذه الدّراسة على درجة ممارسة معلمي اللغة الإنجليزية لمهارات التعلم الإلكتروني في دولة الكويت. ويتحدد تعميم نتائج الدِّراسة بصدوق أداتهيها وثباتهما

منهـج اللِّراسـة: اعتمد الباحثان المنهج الوصفي لإجراء الدِّراسـة، لمناسبته طبيعة الدِّراسة وأهدافها.

$$
\text { مجتمِع الدِّراسـة: }
$$

تكوّن مجتمع الدِّراسـة من معلمي اللغة الإنجليزية للمرحلة الثانوية العاملين في المدراس الحكومية التابعة لمنطقة الأحمدي التعليمية في محافظة

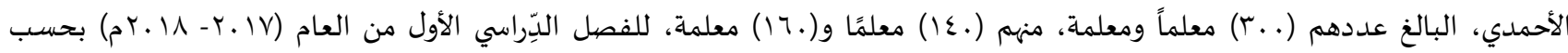
إحصائيات المنطقة التعليمياة.

عينة الدِّراسـة: تكونت عينة الدِّراسة من (.01) معلماً ومعلمة في اللغة الإنجلينية، بنسبة (.0\%) من مجتمع الدِّراسة الأصلي، جرى اختيارهم بالطريقة العشوائية الطبقية البسيطة، والجدول (ا) يوضح ذلك. 
الجدول(1) التكرارات والنسب المئوية حسب متغيرات الدِّراسة

\begin{tabular}{|c|c|c|c|}
\hline النسبة المئوية & التكرار & الفئات & المتغير \\
\hline$\varepsilon 7, V$ & $v$. & ذكر & \multirow[t]{2}{*}{ الجنس } \\
\hline or, r & $\Lambda$. & أنثى & \\
\hline $7 .,$. & 9. & بكالوريوس & \multirow[t]{2}{*}{ المؤهل } \\
\hline$\varepsilon, .$, & 7. & دراسات عليا & \\
\hline $\mathrm{M}, \mathrm{V}$ & 7. & أقل من ه سنوات & \multirow[t]{2}{*}{ الخبرة } \\
\hline $7 r, r$ & 9. & ه سنوات فأكثر & \\
\hline $1 \ldots$, & 10. & المجمموع & \\
\hline
\end{tabular}

أداة الدِّراسـة:

استخدم الباحثان الاستبانة أداة الدِّراسة لجمع البيانات بهدف الدِّراسة، ولإعدادها قام الباحثان بمراجعة الأدب التربوي والدِّراسات السابقة

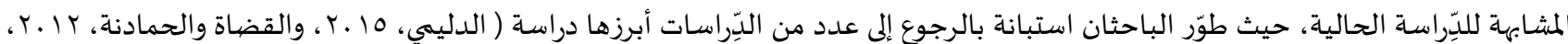

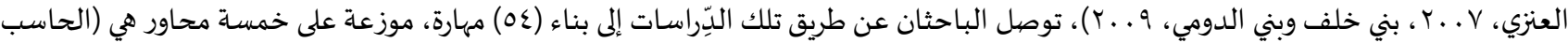

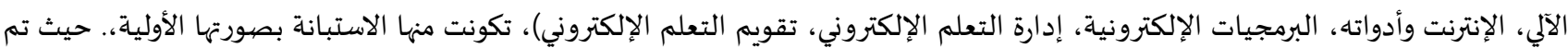

الاعتماد على مقياس ليكرت الخماسي: وهي: درجة (1) قليلة جداً، ودرجة قليلة (؟)، ودرجة (r) متوسطة، ودرجة (ع) كبيرة، ودرجة (0) كبيرة جداً.

صديدق أداة الدِّراسة: قام الباحثان بعدد من الإجراءات للتأكد من صدق أداة الدِّراسة أبرزها: عرض أداة الدِّراسة بصهورتها الأولية والمكونة من (عه) فقرة لاستبانة

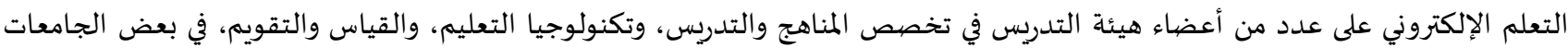
الأردنية وجامعة الكويت والهيئة العامة للتعليم التطبيقي والتدريب كلية التربية الأساسية بدولة الكويت، وطلب الباحثان من المحكمين إبداء رأههم حول

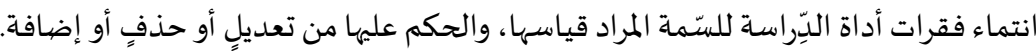
وبعد إجراء عملية التحكيم أجريت التعديلات المطلوبة من قبل المحكمين، حيث تم حذف مهارة البرمجيات الإلكترونية، وتم حذف بعض ادفر الفقرات

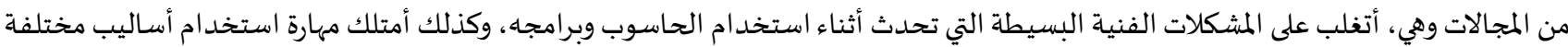

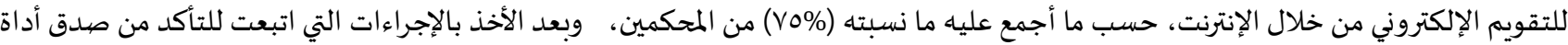

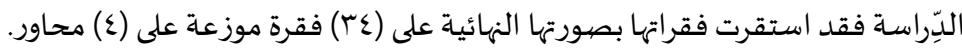

ثبات أداة الدِّراسـة:

للتأكد من ثبات أداة الدِّراسـة، فقد تم التحقق بطريقة (Test- Retest) بتوزيعها، وإعادة توزيعها بعد أسبوعين على مجموعة من خارج أفراد

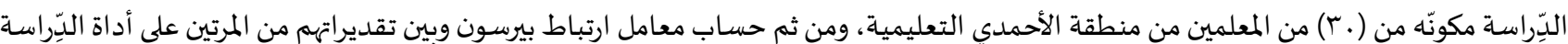

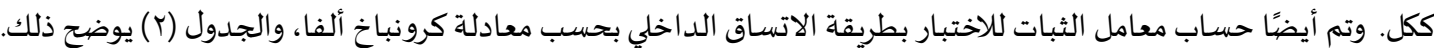

الجدول (r): معامل الاتساق الداخلي كرونباخ ألفا وثبات الإعادة للمجالات والدرجة الكلية

\begin{tabular}{|c|c|c|}
\hline معامل بيرسون بطريقة بيرسون & معامل الثبات بطربقة (كرونباخ ألفا) & المجال \\
\hline$\cdot, 19$ &., 91 & مهارة الحاسب الآلي \\
\hline., 9 . &.,$\Lambda \mathrm{V}$ & مهارة الإنترنت وأدواته \\
\hline., 94 & $\cdot, 9$ & مهارة إدارة التعلم الإلكتروني \\
\hline$\cdot, 9 \varepsilon$ &., 94 & مهارة تقويم التعلم الإلكتروني \\
\hline . 97 & .,9. & الأداة ككل \\
\hline
\end{tabular}

يظهر من الجدول (Y) أنَّ الثبات الكلي بطريقة كرونباخ ألفا بلغ (.9, .)، وبطريقة بيرسون (79, . ). إجراءات الدِّراسـة:

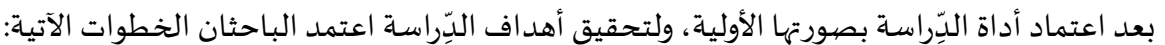
ا. . مراجعة الأدب النظري والدِّرسات السـابقة، ثم إعداد الأداة بصيورتها والمكونة من (عَ) فقرة موزعة على (ع) محاور. 
r. جرى التحقق من ثبات أداة الدِّراسـة بعد تطبيقها على عينة استطلاعية مكونة من (.r) معلمًا ومعلمة من خارج أفراد الدِّراسـة.

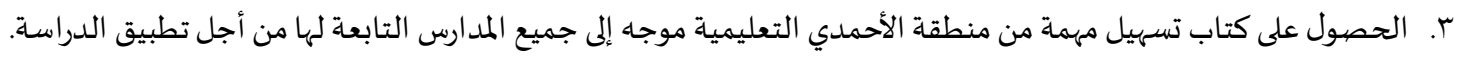

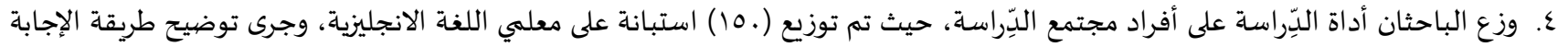

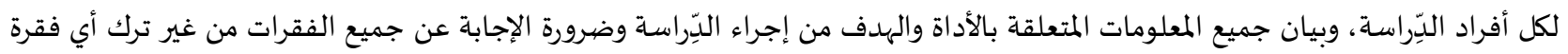

0. جمع استجابات المعلمين والمعلمات حيث تم استرداد جميع الاستبانات والبالغ عددها (10) استبانة، وتم تدقيقها لبيان صلاحيتها للتحليل الإحصائي، ثم قام الباحثان بتصنيفها بحسب متغيراتها. وبعد الانتهاء منها أدخلت إلى الحاسوب، واستخدمت حزمة التحليل الإحصائي (spss ) لاستخراج النتائج.

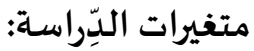
المتغيرات المستقلة ولها ثلاثة مستويات:

r
r-
r- المؤهل العنس وله مستويان:

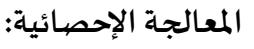

1 - معامل ارتباط بيرسون ( معامل إعادة الثبات) لحساب ثبات التطبيق.

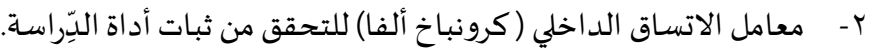

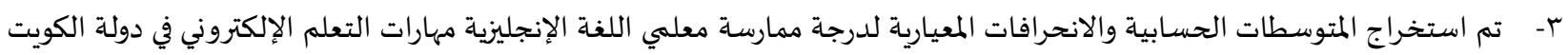
مرتبة تنازليًا حسب المتوسطات الحسابية.

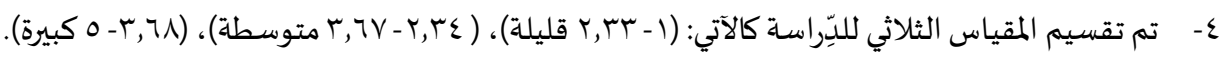

\section{نتائج اللِّراسة ومناقشتهـا:} للإجابة عن السؤال الأول ونصهاء: ما درجة ممارسة معلمي اللغة الإنجليزية لمهارات التعلم الإلكتروني؟ قام الباحثان باستخراج المتوسطات

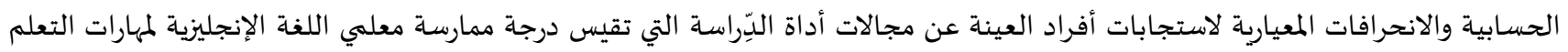
الإلكتروني، والجدول(r) يوضح ذلك. الجدول (r): المتوسطات الحسابية والانحرافات المعيارية لإجابات أفراد العينة على مجالات الدِّراسة والأداة ككل مرتبة تنازلياً

\begin{tabular}{|c|c|c|c|c|c|}
\hline 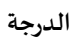 & الانحراف المعياري & المتوسط الحسابي & 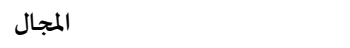 & 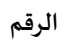 & 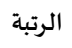 \\
\hline كبيرة & $\cdot, \mathrm{V} \cdot \mathrm{V}$ & $\varepsilon, r$ r & مهارة الحاسب الآلي & 1 & 1 \\
\hline 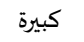 &.,$V T \varepsilon$ & $\varepsilon, .1$ & مهارة الإنترنت وأدواته & r & r \\
\hline كبيرة كبرة & $\cdot, \wedge \leqslant 9$ & $r, \mathrm{r}$. & مهارة إدارة التعلم الإلكتروني & $r$ & $r$ \\
\hline كبيرة &., 101 & $r, 79$ & مهارة تقويم التعلم الإلكتروني & $\varepsilon$ & $\varepsilon$ \\
\hline كبيرة & . $7 \leqslant 0$ & $r, q \varepsilon$ & الأداة ككل & & \\
\hline
\end{tabular}

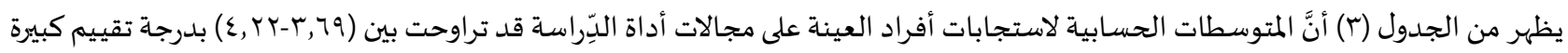

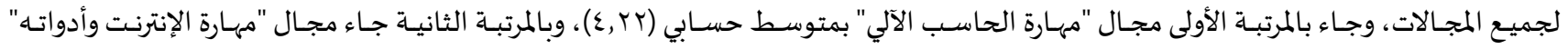

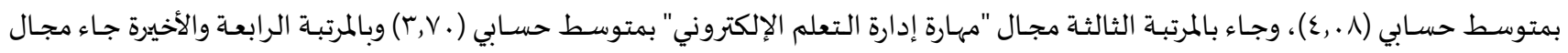

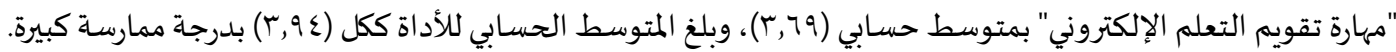

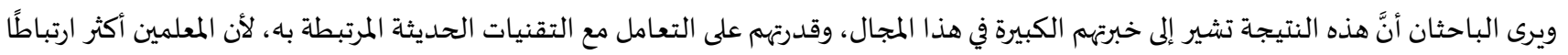

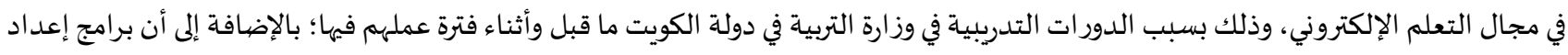
المعلمين في الجامعات تحرص على إكسابهم مهارات التعلم الإلكتروني، وخاصة في مجال استخدام تقنيات التعلم الإلكتروني، كما أن البنية التحتية في

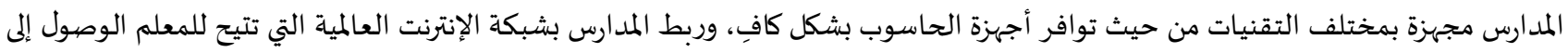


مصادر المعرفة المختلفة، التي تسمح لهم بتطبيق التعلم الإلكتروني على أرض الواقع. اتفقت الدِّراسة في نتائجها مع دراسة العنزي (Y. (Y. (Y)، والتي

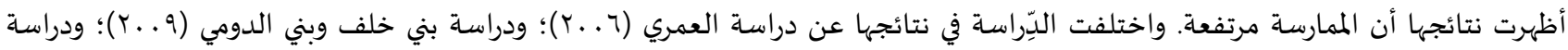

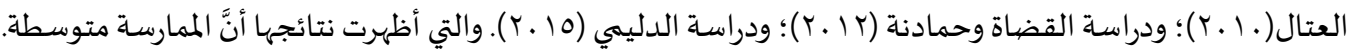

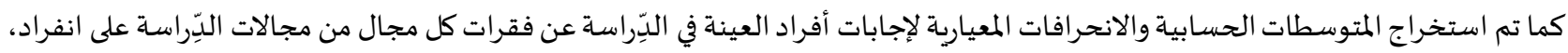
والجداول (乏- (V) توضح ذلك.

الجدول (ع): المتوسطات الحسابية والانحرافات المعيارية لإجابات أفراد العينة على فقرات مجال "مهارة الحاسب الآلي" مرتبة تنازلياً

\begin{tabular}{|c|c|c|c|c|c|}
\hline 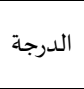 & 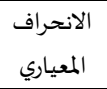 & المتوسط & 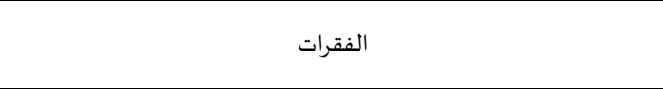 & 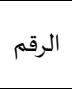 & 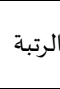 \\
\hline 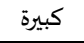 & $\cdot, \wedge 17$ & $\varepsilon, \varepsilon$ & أدير الملفات وأنظمها من إنشاء وحفظ ونسخ ومسح وتعديل. & v & 1 \\
\hline 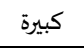 & . Arr & $\varepsilon, r v$ & أشغل نظام النوافذ (windows). & 1 & r \\
\hline 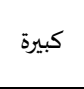 & $\cdot$, А & $\varepsilon, r v$ & التمقت نفسة من التنقل بين البرامج المختلفة بسهولة لأداء أكثير من مهمة في & 9 & $r$ \\
\hline 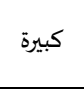 & $\cdot, 9 \wedge \mathrm{V}$ & $\varepsilon, r q$ & 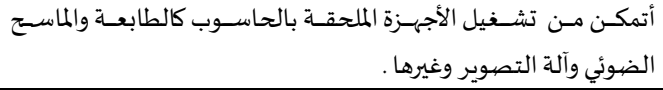 & 7 & $\varepsilon$ \\
\hline كبيرة &., 911 & $\varepsilon, T Y$ & أستخدم الحاسب الآلي في العملية التعليمية التربوية. & $\wedge$ & $\circ$ \\
\hline 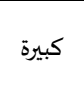 & $\cdot, 9 \cdot 1$ & $\varepsilon, r$ & 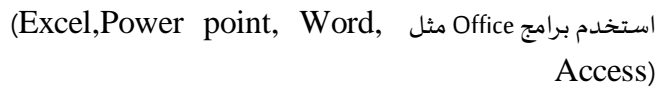 & $\varepsilon$ & 7 \\
\hline 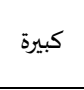 & $\cdot, \wedge 9 \varepsilon$ & $\{, r)$ & والألوانـــ....الخ) بـرامج الوســائط المتعــددة (تحريــر الصــور، والصــوت، & r & $\mathrm{v}$ \\
\hline كبيرة & $1, .77$ & r,qr & أتفحص برامج حماية الحاسوب من الفيروسات. & $\circ$ & $\wedge$ \\
\hline 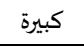 & $1,1 \leqslant r$ & $r, \wedge 9$ & أستطيع ضغط الملفات وفكها باستخدام أحد برامج فك الضغط. & r & 9 \\
\hline 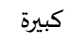 & $\cdot, \mathrm{V} \cdot \mathrm{V}$ & $\varepsilon, r_{T}$ & مجال "مهارة الحاسب الآلي" ككل & & \\
\hline
\end{tabular}

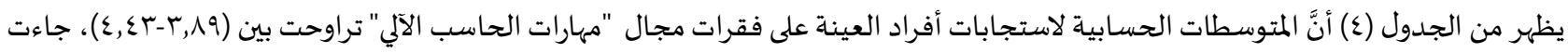

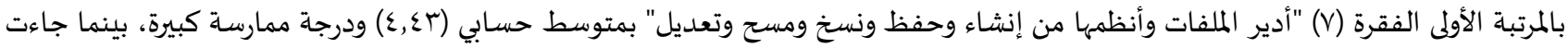

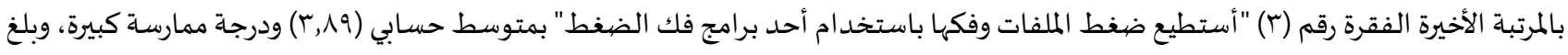

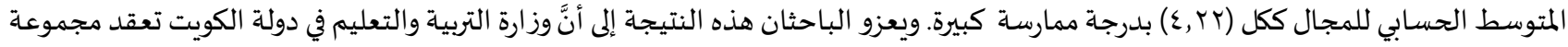

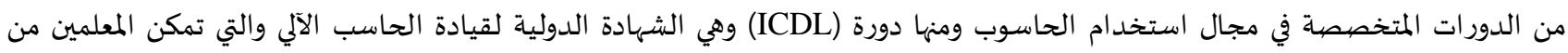

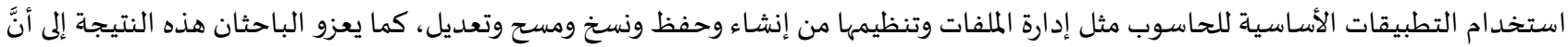

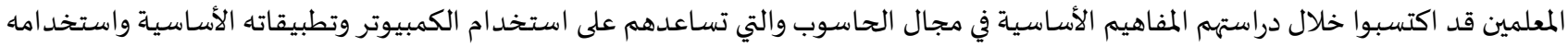

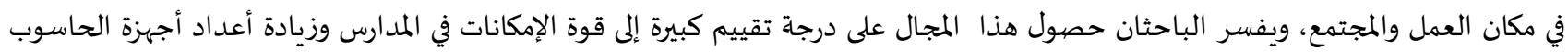

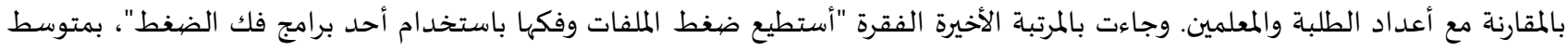

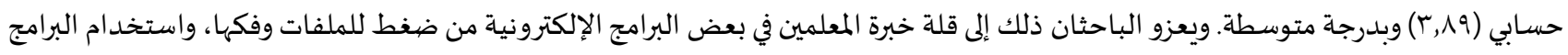

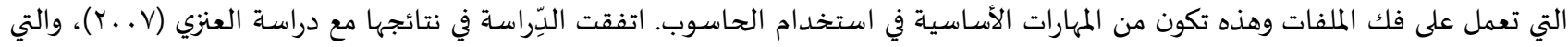

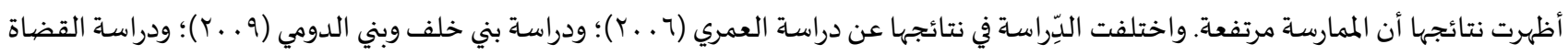

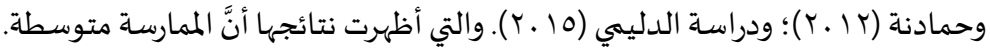


الجدول (0): المتوسطات الحسابية والانحرافات المعيارية لإجابات أفراد العينة على فقرات مجال "مهارة الإنترنت وأدواته" مرتبة تنازلياً

\begin{tabular}{|c|c|c|c|c|c|}
\hline 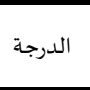 & الانحراف المعياري & المستوسط & 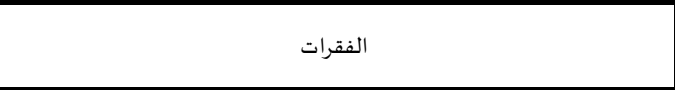 & 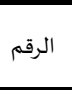 & 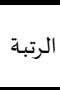 \\
\hline كبيرة & $\cdot, \lambda \cdot \wedge$ & $\varepsilon, \varepsilon \vee$ & أتابع الإصدارات العلمية والبرمجيات الحديثة المتعلقة بتدريس اللغة الإنجليزية & 1 & 1 \\
\hline كبيرة & $\cdot$, , 91 & $\varepsilon, \varepsilon 1$ & 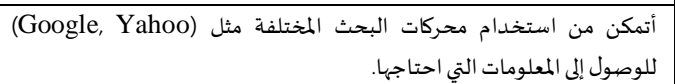 & r & r \\
\hline كبيرة &., $9 \vee$. & $\varepsilon, \uparrow \wedge$ & 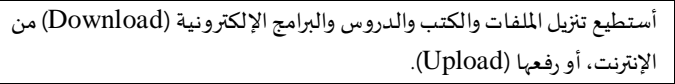 & $\varepsilon$ & $r$ \\
\hline كبيرة &., 190 & $\varepsilon, \mathrm{TV}$ & أشبدد الكلمات المفتاحية المناسبة للوصول إلى المعلومات التي احتاجها عبر & r & $\varepsilon$ \\
\hline كبيرة &., $9 \wedge$. & $\varepsilon, 11$ & أطلعة على الكتب والمراجع والأبحاث المتوفرة عبر الشبكة للاستفادة منها في تدريس & 0 & 0 \\
\hline كبيرة & $1, \ldots 9$ & $r, 97$ & أتمكن من توصيل الحاسب الآلي بشبكة الإنترنت. & 9 & 1 \\
\hline كبيرة & $1, \cdot V T$ & $r, q r$ & ألغة الإنجليزية. المحتوى الإلكتروني للمكتبات للبحث عن المواقع التعليمية المتخصصية في & ^ & v \\
\hline كبيرة & $1, r .$. & $r, \mathrm{rq}$ & أوظف مواقع التواصل الاجتماعي في عملية تدريس اللغة الإنجليزية. & v & $\wedge$ \\
\hline متوسطة & 1,rro & $r, 0$. & أشـارك في المنتديات التعليمية الإلكترونية. & 7 & 9 \\
\hline كبيرة &.,$V r \Lambda$ & $\varepsilon, .1$ & مجال "مهارة الإنترنت وأدواته" ككل & & \\
\hline
\end{tabular}

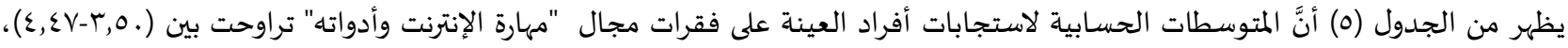

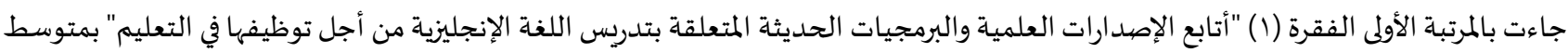

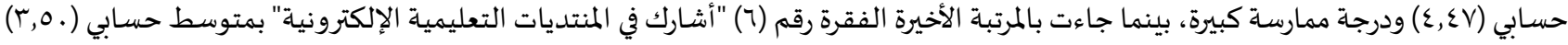

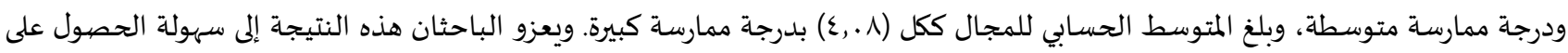

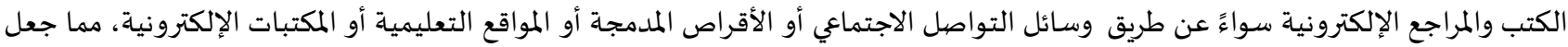

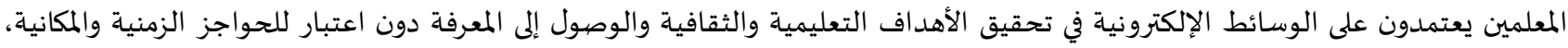

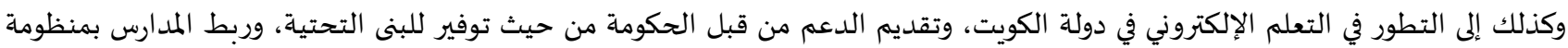

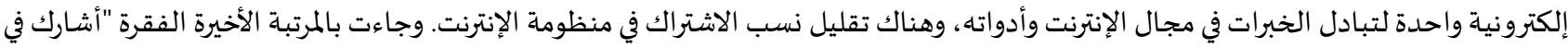

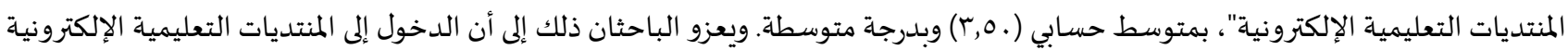
الموجودة على بعض المواقع تتطلب اشتراكات سنوية للدخول إلى تلك البرامج من أجل الاستفادة منها في تدريس الطلبة وهذه الخدمات غير متوفرة في

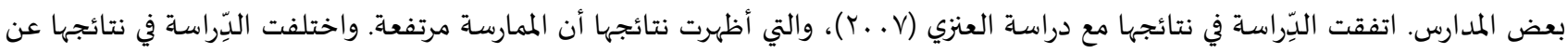

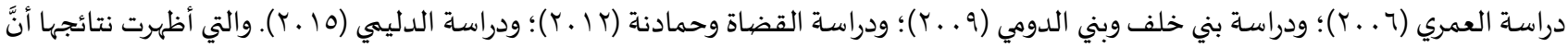

الممارسة متوسطة.

الجدول (7): المتوسطات الحسابية والانحرافات المعيارية لإجابات أفراد العينة على فقرات مجال "مهارة إدارة التعلم الإلكتروني" مرتبة تنازلياً

\begin{tabular}{|c|c|c|c|c|c|}
\hline الدرجة & الانحراف المعياري & الحسابي & 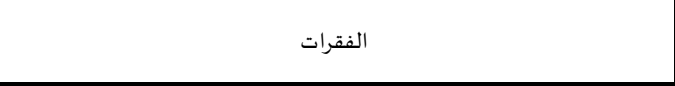 & 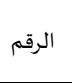 & الرتبة \\
\hline كبيرة & ., १६ V & $r, 90$ & أشجع الطلبة على التفاعل مع المقررات الإلكترونية. & $r$ & 1 \\
\hline كبيرة & $1, . \varepsilon 1$ & $r, \Lambda r$ & أمناسب منها. & 7 & $r$ \\
\hline كبيرة & $1, .19$ & r,vq & التي يواجهونها في التعلم الإلكتروني. ألعاعلة التحاسوب والإنترنت في التفلب على الصعوبات & $\wedge$ & r \\
\hline كبيرة &., 997 & r,vo & أمكن الطلبة من التعلم الذاتي من خلال المقررات الإلكترونية عبر الشبكة. & $\mathrm{v}$ & $\varepsilon$ \\
\hline كبيرة & $1, . \varepsilon v$ & $r, 79$ & الإنترنت الطلبة على المشاركة في المنتديات والمدونات ومجموعات النقاش عبر & r & $\circ$ \\
\hline متوسطة & $1, r 11$ & $r, 7 \varepsilon$ & استخدم أحد أنظمة إدارة التعلم الإلكتروني مثل(Black board, Moodle) & 1 & 1 \\
\hline متوسطة & $1, .9 \mathrm{~V}$ & r,or & أنظم الوقت لتقديم المقرر من خلال الشبكة. & 0 & $\mathrm{v}$ \\
\hline متوسطة & $1,1 \wedge r$ & $r, \varepsilon r$ & أدير النقاش في المجموعات المتاحة عبر الشبكة. & $\varepsilon$ & $\wedge$ \\
\hline 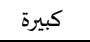 & $\cdot, \wedge \varepsilon 9$ & $r, v$. & مجال "مهارة إدارة التعلم الإلكتروني" ككل & & \\
\hline
\end{tabular}




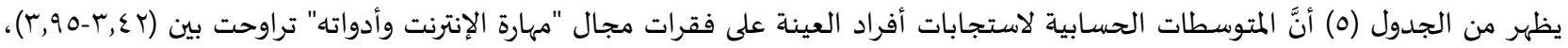

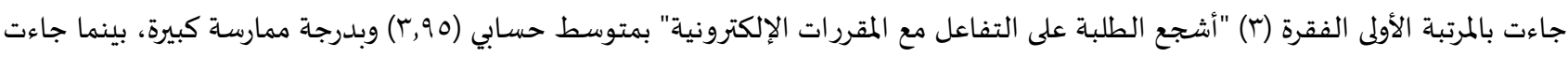
بالمرتبة الأخيرة الفقرة رقم (ع) "أدير النقاش في المجموعات المتاحة عبر الشبكة" بمتوسط حسابي (rع,r) وبدرجة ممارسة متوسطة، وبلغ المتوسط

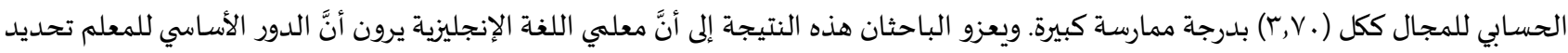

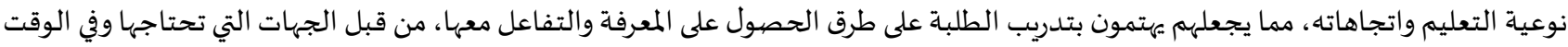

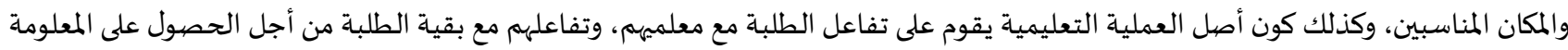
الصحيحة، والتفاعل من أجل الحصول على المعارف المختلفة، وهذا ما دفع المعلمين إلى الاهتمام بهذه المهارة. وجاءت بالمرتبة الأخيرة الفقرة "أدير النقاش في المجموعات المتاحة عبر الشبكة"، بمتوسط حسابي (r ع,r) وبدرجة متوسطة، ويعزو الباحثان ذلك إلى أن تطبيق التعلم الإلكتروني في

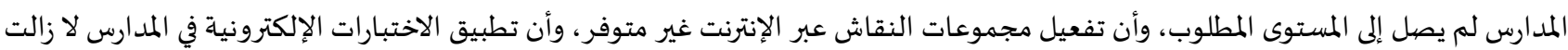

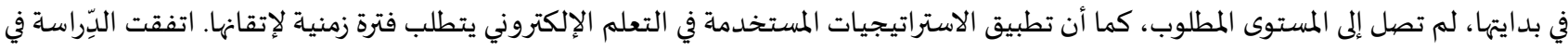

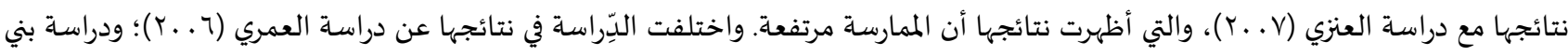

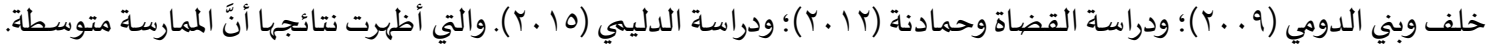

الجدول (V): المتوسطات الحسابية والانحرافات المعيارية لإجابات أفراد العينة على فقرات مجال "مهارة تقويم التعلم الإلكتروني" مرتبة تنازلياً

\begin{tabular}{|c|c|c|c|c|c|}
\hline 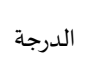 & 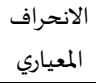 & 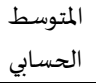 & 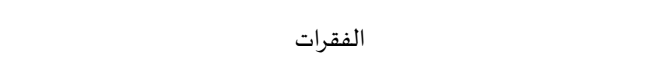 & 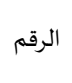 & 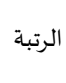 \\
\hline كبيرة & $\cdot, 917$ & $\varepsilon, .1$ & أتقن صياغة الأسئلة بمستويات مختلفة تراعي الفروق الفردية إلكترونياً. & r & 1 \\
\hline كبيرة & $1, . \leq 0$ & $r, A V$ & 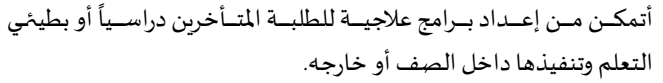 & r & r \\
\hline كبيرة & $1, .71$ & $r, \mathrm{vr}$ & 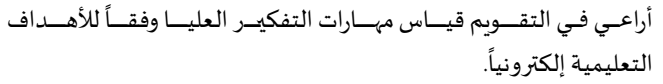 & 7 & $r$ \\
\hline متوسطة & $1, . Y \Lambda$ & $r, 7 \mathrm{r}$ & أضع معايير علمية يتم في ضويها تقويم الطلبة إلكترونياً. & 0 & $\varepsilon$ \\
\hline متوسطة & $1, \cdot 4 \pi$ & $r, 70$ & أستخدم أنواع التقويم ( القبلي - التكويني - النهائي) إلكترونياً. & $\varepsilon$ & 0 \\
\hline 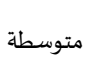 & $1, \ldots 1$ & $r, \pi r$ & ألسكترونياً. & 1 & 7 \\
\hline 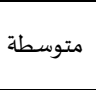 & $1, .91$ & $r, \Sigma 9$ & لتحقيق التعلم. & $\wedge$ & v \\
\hline متوسطة & $1,1 \% 9$ & $r, \varepsilon 7$ & 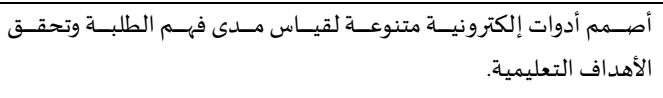 & v & $\wedge$ \\
\hline كبيرة & $\cdot, 101$ & $r, 79$ & مجال "مهارة تقويم التعلم الإلكتروني" ككل & & \\
\hline
\end{tabular}

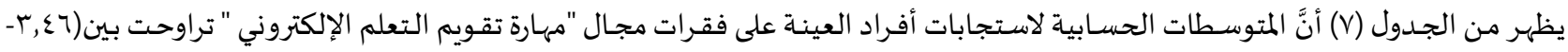

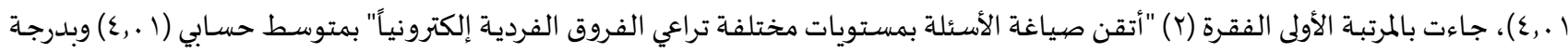

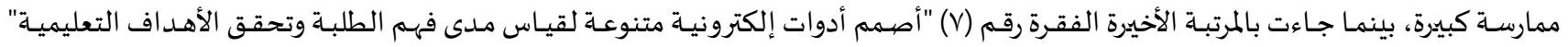

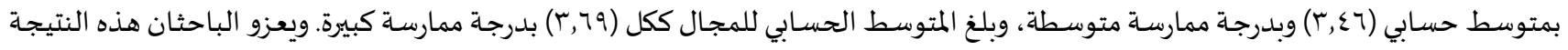

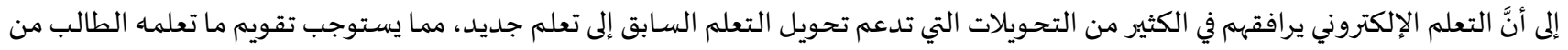

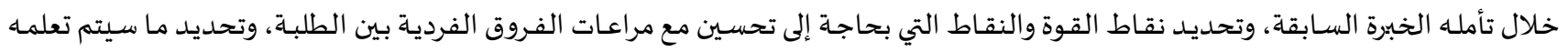

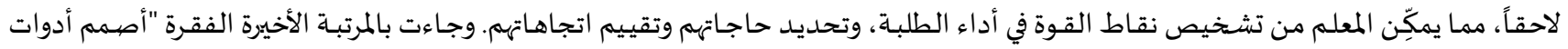

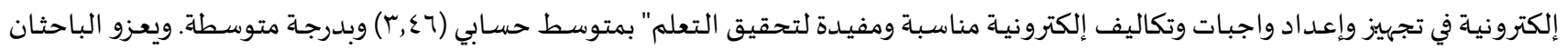

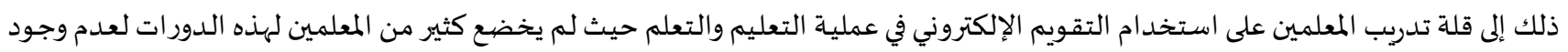

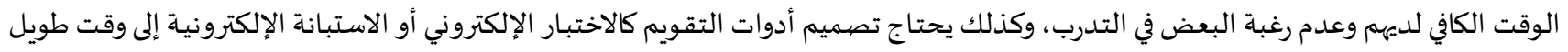

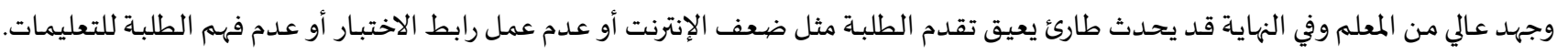

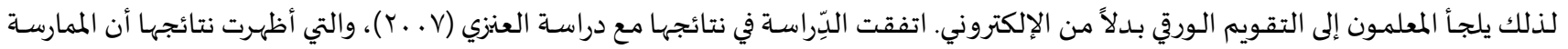




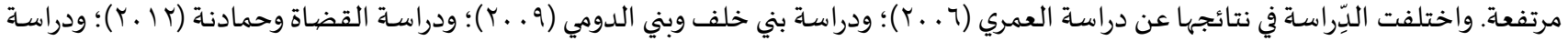

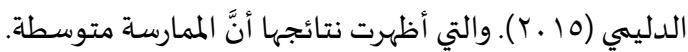
للإجابة عن السؤال الثاني ونصهه: هل تختلف درجة ممارسة معلمي اللغة الإنجليزية لمهارات التعلم الإلكتروني باختلاف (الجنس، والمؤهلات العلميلة، والخبرة التدريسية)؟ قام الباحثان باستخراج المتوسطات الحسابية والانحرافات المعيارية لدرجة ممارسة معلمي اللغة الإنجليزية لمهارات

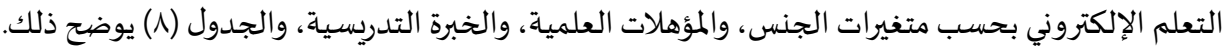

الجدول (^): المتوسطات الحسابية والانحرافات المعيارية لدرجة ممارسة معلمي اللغة الإنجليزية لمهارات التعلم الإلكتروني حسب متغيرات الجنس، والمؤهلات

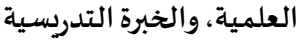

\begin{tabular}{|c|c|c|c|c|c|c|c|}
\hline مهارات التعلم & مهارة تقويم التعلم & مهارة إدارة التعلم & مهارة الإنترنت & مهارة الحاسب الآلي & & الفئات & المتغير \\
\hline$\varepsilon, \cdot r$ & $r, v \varepsilon$ & $r, \Lambda 1$ & $\varepsilon, 1 V$ & $\varepsilon, r_{0}$ & 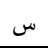 & ذكر & الجنس \\
\hline . $7 V \varepsilon$ &., 90. & ., 19. & $\cdot, \mathrm{V} \cdot \mathrm{l}$ & ( & $\varepsilon$ & & \\
\hline$r, 10$ & $r, 7 \varepsilon$ & $r, 7)$ & $\varepsilon, \ldots$ & $\varepsilon, 11$ & س س & \multirow[t]{2}{*}{ أنثى } & \\
\hline., 71. & .,Y07 &.,$\wedge .0$ & .,$\vee 7 \varepsilon$ & . $v \leqslant 9$ & $\varepsilon$ & & \\
\hline$\varepsilon, .$. & $r, v r$ & $r, v_{0}$ & $\varepsilon, 1 V$ & $\varepsilon, r_{1}$ & س - ا س & بكالوريوس & \multirow[t]{3}{*}{ المؤهل العلهي } \\
\hline . & $\cdot, \wedge$. &., 101 & .,VYT & (1) & $\varepsilon$ & & \\
\hline$r, \lambda r$ & $r, \pi r$ & $r, \pi r$ & $r, 90$ & $\varepsilon, .9$ & س - س & \multirow{2}{*}{ أعلى من بكالوريوس } & \\
\hline., 7.0 & $\cdot, \lambda \cdot \Lambda$ & $\cdot, \wedge \varepsilon \vee$ &.,$V T r$ & . VAY & $\varepsilon$ & & \\
\hline$\varepsilon, \ldots$ & $r, v T$ & $r, V r$ & $\varepsilon, 11$ & $\varepsilon, r_{T}$ & س - س & \multirow[t]{2}{*}{ اقل من ه سنوات } & \multirow[t]{3}{*}{ سنوات الخبرة } \\
\hline ., $7 \leqslant 7$ & . & $\cdot, 101$ &., 779 &., $0 \leqslant V$ & $\varepsilon$ & & \\
\hline r,q. & $r, T V$ & $r, 79$ & $\varepsilon, \cdot Y$ & $\varepsilon, 17$ & 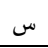 & \multirow[t]{2}{*}{ من 0 سنوات فأكثر } & \\
\hline ., $7 \leqslant \varepsilon$ & - N.r & $\cdot, \wedge \varepsilon \wedge$ & .,VVY & ., VVI & $\varepsilon$ & & \\
\hline
\end{tabular}

س= المتوسط الحسابي ع=الانحراف المعياري

يظهر من الجدول (^) تبايناً ظاهرياً في المتوسطات الحسابية والانحرافات المعيارية لدرجة ممارسة معلمي اللغة الإنجليزية لمهارات التعلم الإلكتروني بسبب اختلاف فئات متغيرات الجنس، والمؤهلات العلمية، والخبرة التدريسية. ولبيان دلالة الفروق الإحصائية بين المتوسطات الحسابية تم استخدام تحليل التباين الثلاثي المتعدد على المجالات الجدولات (9).

الجدول (9): تحليل التباين الثلاثي المتعدد لأثر الجنس، والمؤهلات العلمية، والخبرة التدريسية على مجالات درجة ممارسة معلمي اللغة الإنجليزية لمهارات التعلم الإلكتروني

\begin{tabular}{|c|c|c|c|c|c|c|}
\hline الدلالة الإحصائية & ق ق قيمة ف & متوسط المربعات & درجات الحرية & مجموع المربعات & المجالات & مصدر التباين \\
\hline .,.r. & 0,001 & $r, 777$ & 1 & $r, 777$ & مهارة الحاسب الآلي & الجنس الجن \\
\hline., $11 \mathrm{~V}$ & r,EAT & $1, r T \varepsilon$ & 1 & $1, r T \varepsilon$ & مهارة الإنترنت وأدواته & هوتلنج=044. \\
\hline., $1 \leqslant 7$ & rIE. & $1,0 \leqslant Y$ & 1 & $1,0 \leqslant r$ & مهارة إدارة التعلم الإلكتروني & $.180=\tau$ \\
\hline., $1 \leqslant V$ & . $77 \varepsilon$ & . $\{\wedge \uparrow \uparrow$ & 1 & . $\{$ \&\ & مهارة تقويم التعلم الإلكتروني & \\
\hline., 171 & $1,9 \wedge \varepsilon$ & . $90 \mathrm{r}$ & 1 & . $90 \mathrm{r}$ & مهارة الحاسب الآلي & المؤهل \\
\hline$\cdot, r \cdot 1$ & $1,7 \varepsilon 9$ & $\cdot, \Lambda$. & 1 & $\cdot, \Lambda$. & مهارة الإنترنت وأدواته & هوتلنج=015. \\
\hline.,$\varepsilon 1 Y$ &., $7 \mathrm{VV}$ & $\cdot,\{\wedge \Lambda$ & 1 & $\cdot,\{\wedge$ & مهارة إدارة التعلم الإلكتروني & $.706=\tau$ \\
\hline .,$\varepsilon \wedge 0$ & .,£^9 & . rOA & 1 & ., rOA & مهارة تقويم التعلم الإلكتروني & \\
\hline.,$\varepsilon 1 \wedge$ &., 709 & . & 1 & . & مهارة الحاسب الآلي & 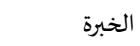 \\
\hline.,$\varepsilon \vee \varepsilon$ &., 017 & . TVO & 1 & . TVO & مهارة الإنترنت وأدواته & هوتلنج=007. \\
\hline$\cdot, 9 \wedge 1$ & $\ldots, \ldots$ &.,$\ldots$ & 1 & $\ldots$ & مهارة إدارة التعلم الإلكتروني & $.908=\tau$ \\
\hline . $9 \mathrm{TV}$ & $\ldots \wedge$ & .,.. & 1 & .,. . & مهارة تقويم التعلم الإلكتروني & \\
\hline
\end{tabular}




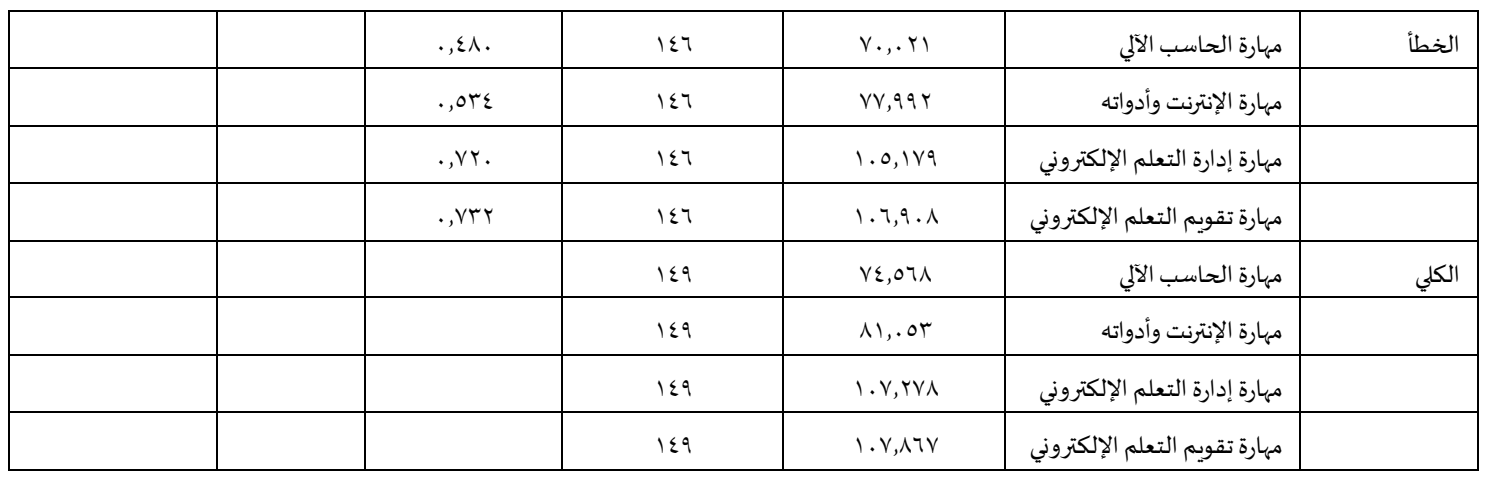

يظهر من الجدول (9) الآتي:

عدم وجود فروق ذات دلالة إحصائية (0. . . =a ) ) تعزى لأثر الجنس في جميع المجالات باستثناء مجال مهارة الحاسب الآلي، وجاءت الفروق لصالح

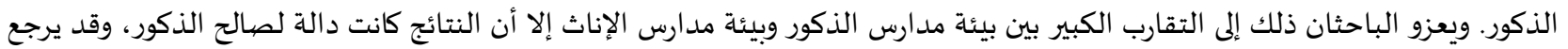

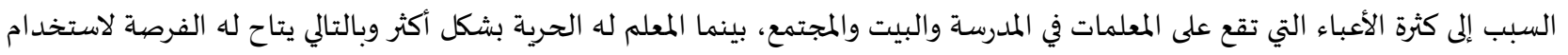

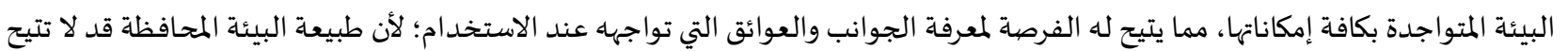

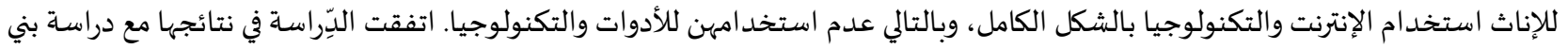

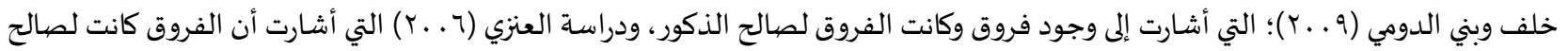

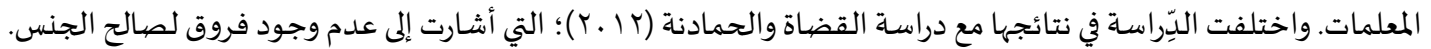
عدم وجود فروق ذات دلالة إحصائية (0. . . = م ) تعزى لأثر المؤهلات العلمية في جميع المجالات. ويعزو الباحثان إلى أن جميع المعلمين والمعلمات على اختلاف مؤهلاتهم يتلقون نفس البرامج التدربية فيما يتعلق بتكنولوجيا المعلومات والاتصالات والتعلم الإلكتروني. اتفقت هذه الدِّراسة في

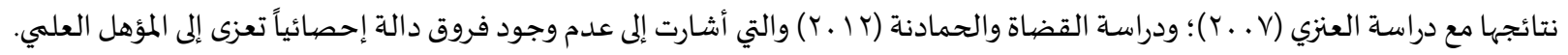
عدم وجود فروق ذات دلالة إحصائية (0. . . =a ) ) تعزى لأثر الخبرة التدريسية في جميع المجالات. ويعزو الباحثان ذلك إلى أن التعلم الإلكتروني من

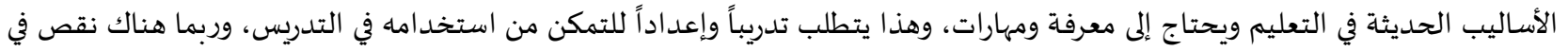

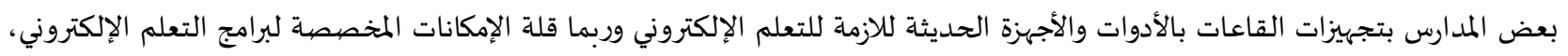

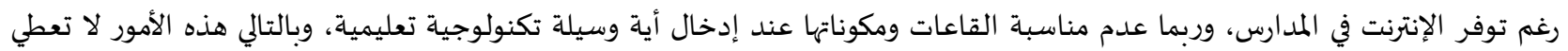

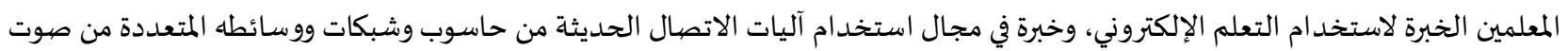

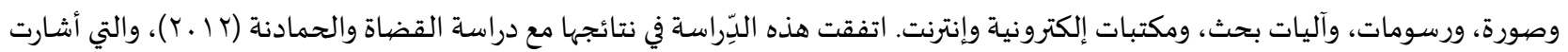

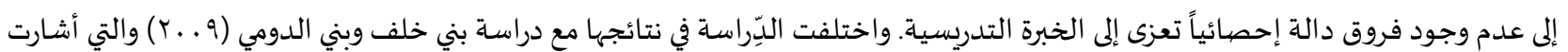

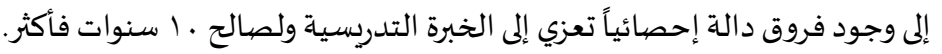

ضرورة توفير متطلبات التعلم الإلكتروني في المدارس، والتأكيد على أهميته في التعلم من خلال إعطاءه حصص محوسبة أكثر. إجراء دورات تعليمياة مستمرة للمعلمين في مجال تكنولوجيا التعليم وكيفية استخدامه. الاستعانة بمختصين في مجال التكنولوجيا لتدريب المعلمين والموجهيين التربويين. ربط المختبرات في المدارس بمصادر التعلم، وتوفير الاتصال بشبكة الإنترنت. التنسيق بين معلم اللغة الإنجليزية ومعلم الحاسوب لتعليم الطلبة المهارات المهمة للتعلم الإلكتروني. ندوات مستمرة، ومساعدة معلمي اللغة الإنجليزية في الوصول على التقنيات الحديثة من خلال دعمهم بشكل مادي ومعنوي. 


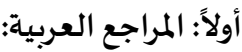

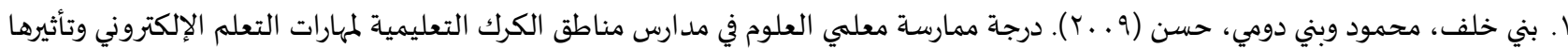

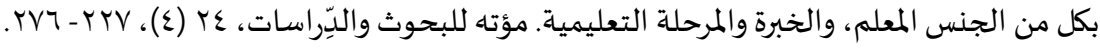

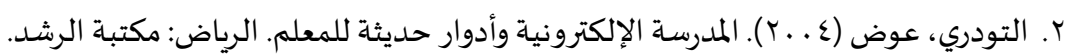

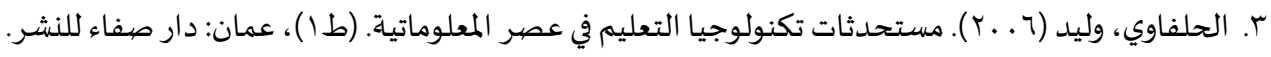

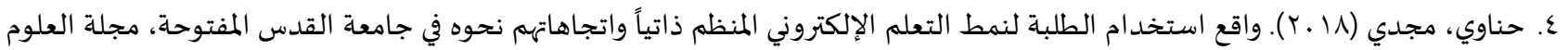

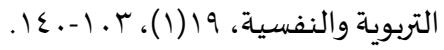

0. الدليمي، صعب (10 .ب). درجة ممارسة معلمي اللغة العربية لمهارات التعلم الإلكتروني وعلاقتها بدافعية طلبتهم نحوه. رسالة ماجستير غير

$$
\text { منشورة، جامعة آل البيت، الأردن. }
$$

7. الراشد، فارس (ץ. . ب). التعلم الإلكتروني واقع وطموح. الندوة الدولية للتعلم الإلكتروني والمقامة بمدارس الملك فيصل بالرياض، مدارس الملك

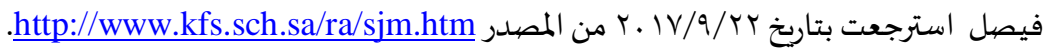

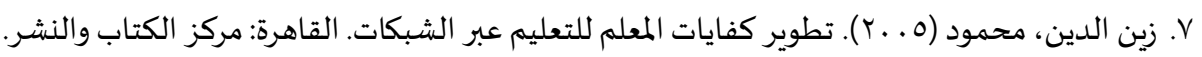

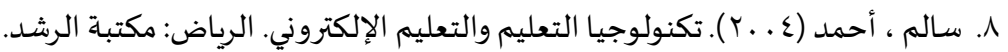

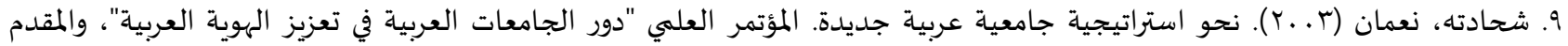

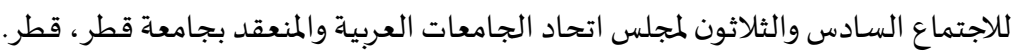

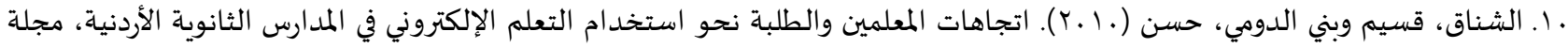

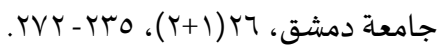

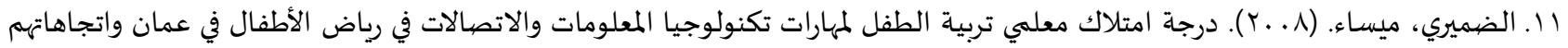

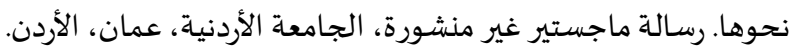

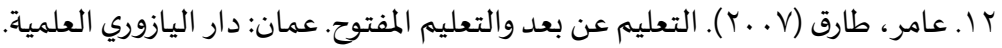

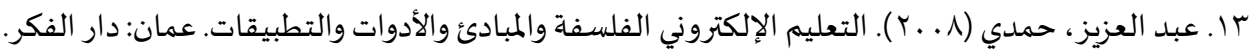

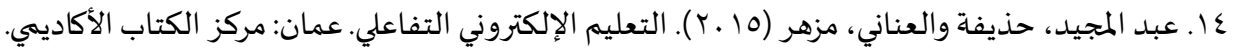

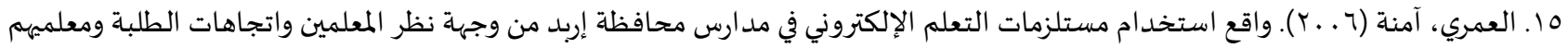
نحوها. رسالة ماجستير غير منشورة، الجامعة الأردنية، عمان، الأردن.

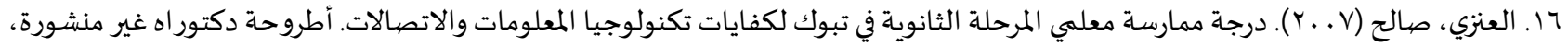
الجامعة الأردنية، الأردن.

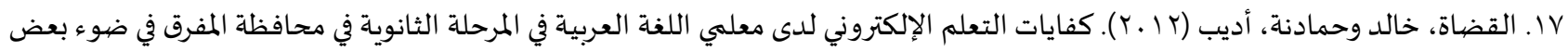

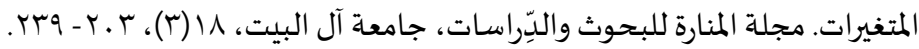

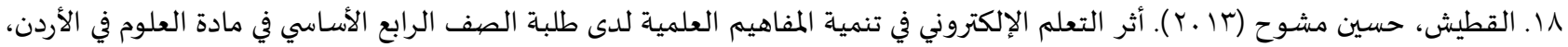

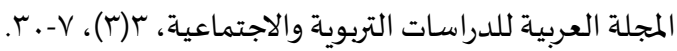
19 ا. المبيريك، هيفاء (r. .ب). تطوير طريقة المحاضرة في التعليم الجامعي باستخدام التعلم الإلكتروني مع نموذج مقترح. ندوة مدرسة المستقبل، جامعة الملك سعود.

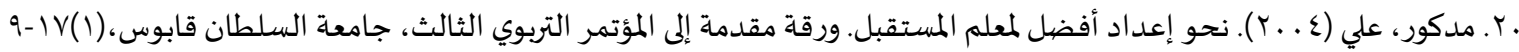

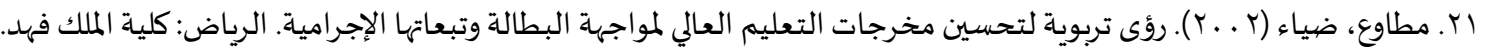

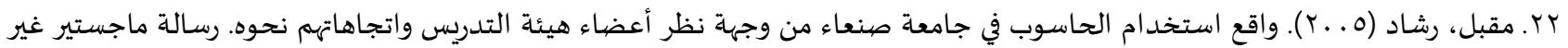
منشورة، جامعة اليرموك، إربد، الأردن.

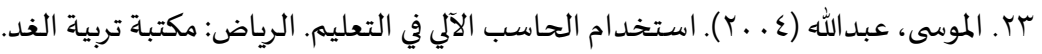

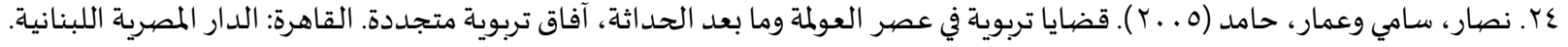


[1] N. Islam, M. Beer \& F. Slack, (2015). E-Learning Challenges Faced by Academics in Higher Education: A Literature Review. Journal of Education and Training Studies, 3(5), 102-112

[2] G. Makokha \& D. Mutisya, (2016). Status of E-Learning in Public Universities in Kenya, International Review of Research in Open and Distributed Learning, 17(3), 341-359.

[3] G. Obuekwe\& R Eze, (2017). Promoting Best Practices in Teaching and Learning in Nigerian Universities through Effective E-Learning: Prospects and Challenges, International Association for Development of the Information Society, Paper presented at the International Association for Development of the Information Society (IADIS) International Conference on E-Learning (Lisbon, Portugal, Jul 20-22, 2017).

[4] C. Sorgenfrei \& S. Smolnik, (2016). The Effectiveness of E-Learning Systems: A Review of the Empirical Literature on Learner Control. Decision Sciences Journal of Innovative Education, 14(2), 154-184. 
Refaad

رفاد للدراسـات والأبحاث

www.refaad.com
المجلة الدولية للدراسات التربوبة والنفسية

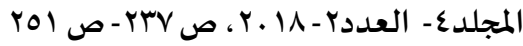

e-ISSN 2520-4149, p-ISSN 2520-4130
المجلة الدولية للدراسات

الثربوية والنفسية

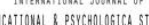

\title{
The Degree of practicing English Teachers at the Skills of E-Learning in Kuwait
}

\author{
Adeeb Theab Hamadneh \\ Professor of Areas of Arabic language and the method taught - AL- Albyat University- Jordan \\ adeebhamadnah@yahoo.com
}

Ghazil Bader Al Ghasab

Teacher- Ministry of Education English- Kuwait

\begin{abstract}
:
This study aims to identify the degree to which English language teachers practiced e-learning skills, and the impact of the following variables: gender, educational qualifications and years of experience on this. The descriptive method was employed with a selected sample of (150) female and male teachers. the instrument of study consisted of (34) items, distributed on four themes. The reliability and validity were checked

The results of the study revealed several findings, the most important of which are: the degree of practice of English language teachers in e-learning skills was very high. The results of the study also showed that there were no statistically significant differences $(\alpha=0.05)$ due to the impact of sex in all fields, except computer skills and the differences came in favor of male teachers. The results also suggested that there were no statistically significant differences $(\alpha=0.05)$ due to the impact of educational qualifications and teaching experience in all fields. In light of these findings the study recommends there is a need to have specialists in the fields of technology and the Internet in schools to help teachers to practice the skills of e-learning.
\end{abstract}

Keywords: The degree of practicing, E- learning skills, English teachers. 